Review

\title{
Structured adsorbents in gas separation processes
}

\author{
F. Rezaei, P. Webley* \\ Department of Chemical Engineering, Monash University, Wellington Road, Clayton, VIC 3800, Australia
}

\section{A R T I C L E I N F O}

\section{Article history:}

Received 31 March 2009

Received in revised form 4 October 2009

Accepted 6 October 2009

\section{Keywords:}

Structured adsorbent

Adsorptive gas separation

Pressure drop

Novel adsorbents

Mass transfer

\begin{abstract}
A B S T R A C T
In this review, novel structured adsorbents for gas separation processes are discussed. General requirements are elucidated and illustrated with respect to specific structures such as monoliths, foams, laminates, and fabric structures. Geometrical parameters of adsorbents which affect the system performance are identified and discussed. It is clear that opportunities for improvement and optimization of adsorptive gas separation processes should include the development of improved structured adsorbents. These novel structures can fulfil many of the requirements of advanced gas separation processes such as enhanced mass transfer, reduced pressure drop, and improved thermal management.
\end{abstract}

(c) 2009 Elsevier B.V. All rights reserved.

\section{Contents}

1. Introduction

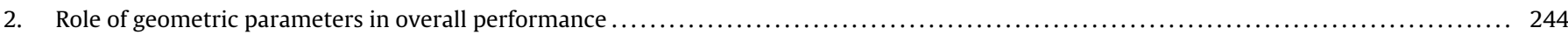

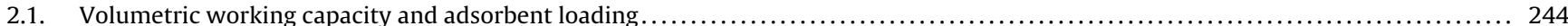

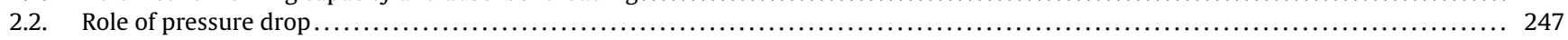

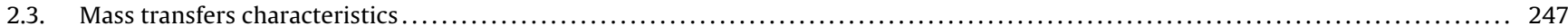

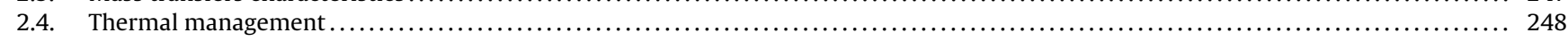

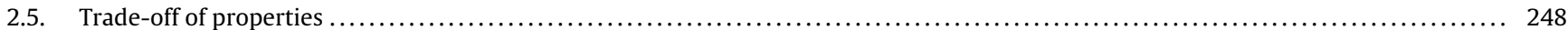

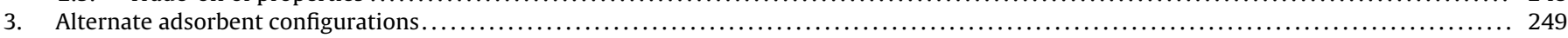

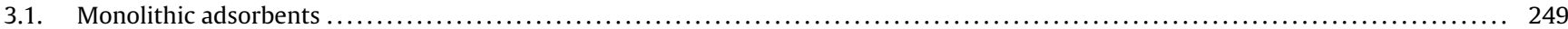

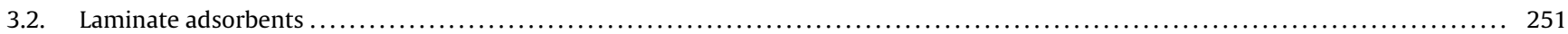

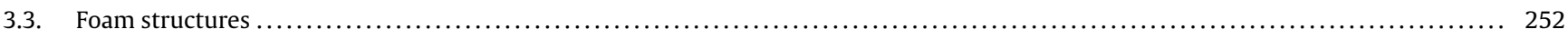

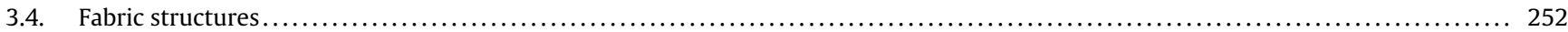

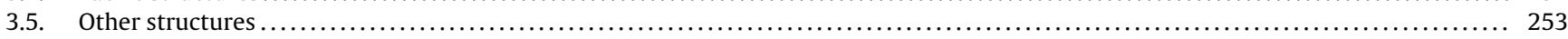

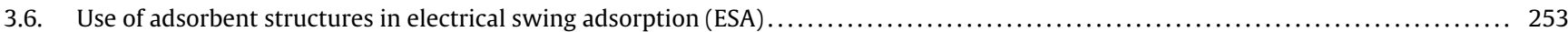

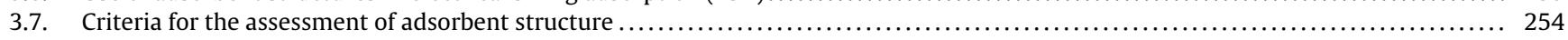

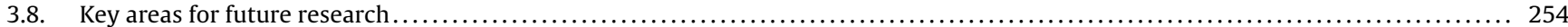

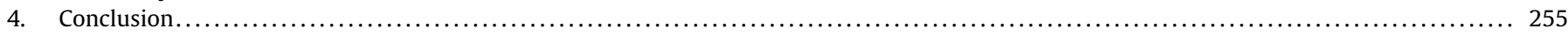

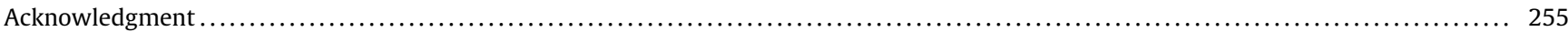

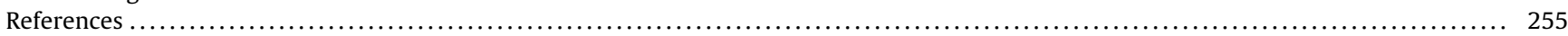

\section{Introduction}

Developments in adsorption processes usually focus attention on improved adsorbents especially with regard to the adsorption isotherm and selectivity for the separation of interest. However, improvements in performance and reduction in cost of cyclic adsorption processes including pressure swing adsorption (PSA)

\footnotetext{
* Corresponding author. Tel.: +61 39905 3445; fax: +61 399055686

E-mail address: paul.webley@eng.monash.edu.au (P. Webley).
}

and temperature swing adsorption (TSA) are also dependent on parameters which are dictated by adsorbent loading per unit volume, mass transfer properties, pressure drop, and thermal management. These factors play an important role in the size of the process equipment, the attainable product recovery, and the resulting power consumption. All of these affect system cost. These factors are strongly influenced by the structure of the adsorbent used in the gas separation device.

Over the last decade, there has been considerable interest in the intensification of separation processes. In cyclic devices such as PSA and TSA, reducing cycle time is the primary means of achiev- 
ing more production from a given quantity of material. However, as cycle time is reduced, cyclic devices usually face the problem of decreasing working capacity per cycle for the component of interest, decreasing product recovery and increasing pressure drop. The extent to which cycle time reduces working capacity and recovery and increases pressure drop is dependent on the structure of the adsorbent. Conventional gas separation systems are usually performed using adsorbents in the form of beads or granules. However, mass transfer and pressure drop drawbacks associated with conventional packed beds impose limitations in operating the process at optimum conditions in terms of energy consumption and overall system efficiency. Reducing particle size is the most obvious way to decrease mass transfer resistance (which varies as the square of particle size) and trends over the last few decades have seen particle sizes reducing from 2 to $3 \mathrm{~mm}$ down to less than $0.7 \mathrm{~mm}$. Combating the accompanying increase in pressure drop with reduction in particle size has led to bed geometries of a "pancake" nature, i.e. $L / D$ ratios considerably less than one. However, considerable gas maldistribution and channelling not to mention potential fluidization of packed beds are issues which emerge when shallow, large diameter packed beds are used.

An alternate approach to simply reduce particle size is to investigate entirely non-particulate, novel adsorbent structures. Alternate adsorbent geometries should satisfy a number of requirements in order to be considered as suitable candidates for the replacement of pellet/bead configurations. In particular, such structures should yield high mass transfer kinetics with large film and solid mass transfer coefficients. Furthermore, they must exhibit high volume working capacity (loading per unit system volume) as well as low voidage for minimizing the size of the adsorber. In addition, the gas flow path in these novel adsorbent structures should produce low pressure drop to minimize energy consumption. Finally, the use of novel adsorbent structures permits simultaneous engineering of heat transfer into the adsorbent, an often overlooked consideration in design of adsorption processes. By this is meant the process of heat transfer to/from the gas and the adsorption sites. Since adsorption is exothermic and desorption endothermic, a thermal swing accompanies the pressure swing and is usually detrimental to the overall system performance, sometimes by as much as $30 \%$. Efficient transfer of heat to and from the adsorbent can significantly improve system performance and a structured adsorbent affords opportunities to accomplish this.

The present review examines the approaches taken in the published literature on fundamental and applied research of adsorbent geometries using novel adsorbent structures in gas separation systems. The review highlights in particular, monoliths, laminates, foams and fabrics structures along with their applications in adsorption based gas separation processes. The role of the geometric parameters of these structured adsorbents is also evaluated. The aim in this review is to illustrate and analyse recent advances in the application of novel adsorbents in gas separation and purification processes. Finally, based on the review, a number of suggestions for future research are made. Fig. 1 illustrates some typical adsorbent structures which have been used either commercially or in research studies.

Table 1 summarizes a large number of studies in which nonparticulate adsorbent structures have been used with the key results reported. These will be discussed in more detail below.

\section{Role of geometric parameters in overall performance}

A number of physical adsorbent parameters govern the performance of adsorptive gas separation processes for a given adsorption isotherm. As mentioned above, these parameters include volumetric working capacity, pressure drop, mass transfer characteristics,

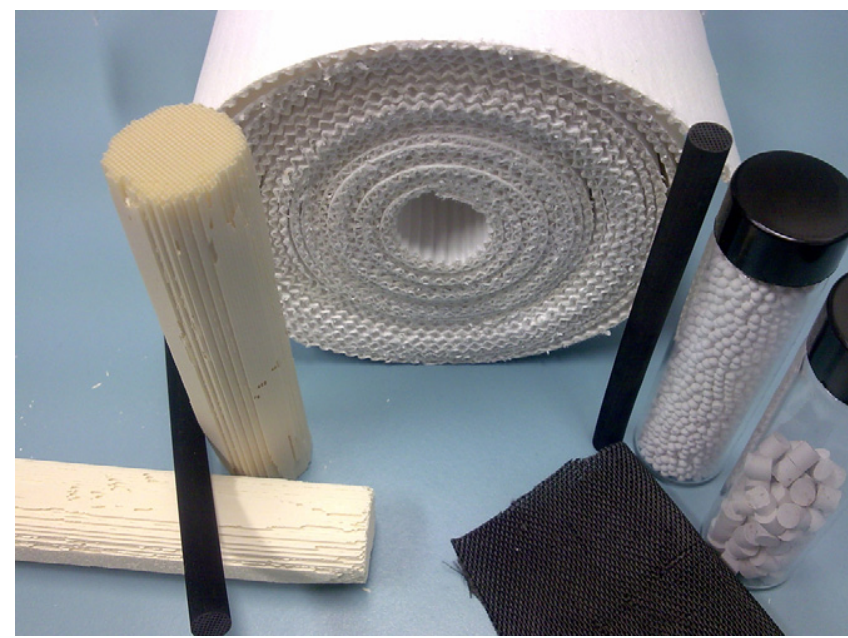

Fig. 1. Illustration of a variety of adsorbent structures including (left to right): ceramic and carbon adsorbent monoliths, corrugated paper monoliths (center), fabric adsorbent and conventional beaded adsorbents.

as well as thermal management. It is possible to develop a structured adsorbent with superior performance to a packed bed (on a volume or mass basis) provided the parameters listed above are at their "optimal" values. However, care must be taken when using a structured adsorbent for a particular process since there is always a trade-off between these aforementioned parameters during operation.

\subsection{Volumetric working capacity and adsorbent loading}

Volumetric working capacity is defined here as the moles of gas processed per unit volume per cycle. This is a product of the working capacity (moles of gas adsorbed/desorbed per unit mass of adsorbent including binder, support, etc.) and the density of the composite adsorbent. The throughput attainable in a given volume of vessel in a cyclic adsorption system may be expressed as:

Throughput $\left(\mathrm{mole} / \mathrm{s} \mathrm{m}^{3}\right)=\frac{W C * \rho_{B}}{\tau}$

where $W C$ is the working capacity (moles/kg adsorbent/cycle), $\rho_{B}$ is the bulk adsorbent density ( $\mathrm{kg}$ adsorbent $/ \mathrm{m}^{3}$ ) and $\tau$ is the cycle time (s/cycle). Although structured adsorbents are developed with the aim of operation at faster cycle times (lower $\tau$ ), any development which simultaneously reduces adsorbent density $\left(\rho_{B}\right)$ is detrimental to throughput. Thus although structured adsorbents may have remarkable advantages over adsorbent pellets such as fast mass transfer kinetics (due to shorter diffusion path) and easier heat transfer in all directions, as well as more uniform temperature distribution, their throughput is often lower, since the adsorbent loading on a mass or volume basis is often small compared to adsorbent materials in the form of pellets/beads.

It is worth mentioning that high adsorbent loading may not always be a desirable parameter in all adsorptive processes if other features are compromised. For instance, in some adsorptive systems, mass and heat transfer processes dominate system performance (e.g. removing moisture from air) and hence reducing the characteristic diffusion length may necessitate the use of thin layers of adsorbent which may actually lead to reduced adsorbent loading. In terms of Eq. (1), high $\rho_{B}$ may compromise WC and hence an optimum loading may exist.

A feature related to adsorbent loading which becomes increasingly important as cycle time is reduced is "switching" losses. Switching losses are losses in throughput and separation due to pressurizing and depressurizing "dead" space. These losses become 
A summary of structured adsorbent applications in adsorptive processes.

\begin{tabular}{|c|c|c|c|c|c|}
\hline Reference & Structure & Packing details & System & Experimental conditions & Results \\
\hline Kodama et al. [21] & Monolith & $\begin{array}{l}\text { Honeycomb rotor with a thin } \\
\text { sheet of silica gel }\end{array}$ & Air dehumidification & $\begin{array}{l}\text { Air velocity of } 1.2 \mathrm{~m} / \mathrm{s} \text { through } \\
\text { a } 0.2-\mathrm{m} \text { long honeycomb }\end{array}$ & $10-20 \%$ humidity reduction \\
\hline Gadkaree [23] & Monolith, $400 \mathrm{cpsi}$ & $\begin{array}{l}\text { Activated carbon honeycomb } \\
\text { structures }\end{array}$ & VOC removal & $\begin{array}{l}\text { Honeycombs with about } 18 \\
\text { wt\% carbon }\end{array}$ & $\begin{array}{l}\text { Breakthrough curves similar to } \\
\text { packed beds }\end{array}$ \\
\hline Li et al. [24] & Monolith & 5A zeolite monolith & Oxygen-enriched air & 3.8 bar feed pressure & $3-5$ times lower pressure drop \\
\hline Brandani et al. [32] & Monolith & Carbon monolith & $\mathrm{CO}_{2}-\mathrm{He}$ and $\mathrm{CO}_{2}-\mathrm{N}_{2}$ & $\begin{array}{l}\text { Pressure: } 23 \text { Torr, temperature: } \\
23^{\circ} \mathrm{C}\end{array}$ & $\begin{array}{l}\text { Dispersion is controlled by mass } \\
\text { transfer resistance rather than } \\
\text { axial dispersion }\end{array}$ \\
\hline Yates et al. [34] & Monolith, 50 cpsi & Honeycomb monolith & $\begin{array}{l}\text { Effluent gas } \\
\text { purification }\end{array}$ & $\begin{array}{l}\text { Pressure: } 1 \mathrm{~atm} \text {, temperature: } \\
\text { room temperature }\end{array}$ & $\begin{array}{l}\text { Allowing adsorbent regeneration } \\
\text { up to } 300^{\circ} \mathrm{C}\end{array}$ \\
\hline Yu et al. [35] & Monolith, $400 \mathrm{cpsi}$ & Activated carbon monolith & VOC removal & $\begin{array}{l}\text { Pressure: } 1 \mathrm{~atm} \text {, temperature: } \\
20,60,100 \text {, and } 140^{\circ} \mathrm{C}\end{array}$ & $\begin{array}{l}\text { Good correlation of VOCs } \\
\text { adsorption data on activated } \\
\text { carbon monolith using } \\
\text { Langmuir-Freundlich and Toth } \\
\text { equations }\end{array}$ \\
\hline Valdes-Solis et al. [37] & Monolith, 200-900 cpsi & $\begin{array}{l}\text { Carbon-coated ceramic } \\
\text { monoliths }\end{array}$ & VOC removal & $\begin{array}{l}\text { Pressure: } 1 \mathrm{~atm} \text {, temperature: } \\
\text { room temperature }\end{array}$ & $\begin{array}{l}\text { Better breakthrough performance } \\
\text { than a packed bed }\end{array}$ \\
\hline Grande et al. [41] & Monolith, 424,900 cpsi & 4A honeycomb monolith & $\begin{array}{l}\text { Propane and propylene } \\
\text { adsorption }\end{array}$ & $\begin{array}{l}\text { Pressure: } 1.5,5.6 \text { and } 10.0 \mathrm{kPa} \text {, } \\
\text { temperature: room } \\
\text { temperature }\end{array}$ & $\begin{array}{l}\text { Smaller diffusivity coefficients } \\
\text { than extrudates }\end{array}$ \\
\hline Cutler et al. [44] & Monolith, 50-3000 cpsi & Honeycomb monolith & $\begin{array}{l}\text { Desulphurization } \\
\text { process }\end{array}$ & $\begin{array}{l}\text { Pressure: } 1 \mathrm{~atm} \text {, temperature: } \\
25-400^{\circ} \mathrm{C}\end{array}$ & Lower pressure drop per volume \\
\hline Ribeiro et al. [45] & Monolith, $300 \mathrm{cpsi}$ & $\begin{array}{l}\text { Activated carbon honeycomb } \\
\text { monolith }\end{array}$ & $\begin{array}{l}\mathrm{CO}_{2}, \mathrm{CH}_{4} \text {, and } \mathrm{N}_{2} \\
\text { Adsorption }\end{array}$ & $\begin{array}{l}\text { Pressure: } 1 \mathrm{~atm} \text {, temperature: } \\
303-423 \mathrm{~K}\end{array}$ & $\begin{array}{l}\text { Adsorption capacity honeycomb } \\
\text { monolith: } \mathrm{CO}_{2}>\mathrm{CH}_{4}>\mathrm{N}_{2}\end{array}$ \\
\hline Jain et al. [46] & Monolith & Monolithic wheel & Air separation & - & Cycle time of $35 \mathrm{~s}$ for rapid PSA \\
\hline Kaboord et al. [48] & Monolith, $120 \mathrm{cpsi}$ & Honeycomb monolith & $\begin{array}{l}\text { Vehicle exhaust } \\
\text { systems }\end{array}$ & - & Suitable for diesel engines \\
\hline Jale et al. [49] & Monolith & Honeycomb monolith & Air separation & - & $\begin{array}{l}\text { Improved } \mathrm{N}_{2} / \mathrm{O}_{2} \text { selectivity and } \mathrm{N}_{2} \\
\text { capacity }\end{array}$ \\
\hline Gorbach et al. [55] & Monolith, 100, 200, $400 \mathrm{cpsi}$ & Zeolite 4A-polyamide monolith & Rapid PSA (RPSA) & $\begin{array}{l}\text { Extrusion of polymer matrices } \\
\text { filled with zeolite powder } \\
\text { using thermoplastic materials } \\
\text { as plasticizing aid and binder }\end{array}$ & $\begin{array}{l}\text { Enhancement of productivity, } \\
\text { lower pressure drop }\end{array}$ \\
\hline Yu et al. [105,106] & Monolith, $400 \mathrm{cpsi}$ & Activated carbon monolith & $\begin{array}{l}\text { Electrothermal swing } \\
\text { adsorption(ESA) }\end{array}$ & $\begin{array}{l}\text { Pressure: } 1 \mathrm{~atm} \text {, temperature: } \\
\text { room temperature }\end{array}$ & High toluene vapour removal \\
\hline Grande and Rodrigues [107] & Monolith, $190 \mathrm{cpsi}$ & $\begin{array}{l}\text { Activated carbon honeycomb } \\
\text { monolith }\end{array}$ & $\mathrm{CO}_{2}$ removal ESA & $\begin{array}{l}\text { Pressure: } 101 \mathrm{kPa} \text { temperature: } \\
297 \mathrm{~K}\end{array}$ & $\begin{array}{l}\mathrm{CO}_{2} \text { recovery: more than } 89 \%, \mathrm{CO}_{2} \\
\text { purity: } 16 \%\end{array}$ \\
\hline Keefer et al. $[66,67]$ and Connor et al. [65] & Laminate & Adsorbent sheet & Rotary PSA, rapid PSA & - & Lower pressure drop \\
\hline Keefer [70] & Laminate & $\begin{array}{l}\text { Laminated parallel passage } \\
\text { contactor }\end{array}$ & PSA system & - & Operation at high frequency \\
\hline Maurer [68] & Laminate & Spirally wound adsorbent & VOC removal & - & $\begin{array}{l}\text { Longer adsorbent life alternative } \\
\text { for a thermal swing adsorption } \\
\text { process }\end{array}$ \\
\hline Ruthven and Thaeron [4] & Laminate & $\begin{array}{l}\text { Parallel passage contactor } \\
\text { coated with ACF sheets }\end{array}$ & $\mathrm{CO}_{2}$ removal & $\begin{array}{l}\text { Pressure: } 1 \mathrm{~atm} \text {, temperature: } \\
\text { room temperature }\end{array}$ & $\begin{array}{l}\text { High selectivity ratio diffusion time } \\
\text { constant of } 10 \mathrm{~ms}\end{array}$ \\
\hline Keefer [70] & Laminate & Layered adsorbent beds & Ultra rapid PSA & - & 100 cycle/min \\
\hline Keefer [67] & Laminate & $\begin{array}{l}\text { Adsorbent laminate coated } \\
\text { with X-zeolite }\end{array}$ & $\begin{array}{l}\text { Oxygen enrichment } \\
\text { PSA }\end{array}$ & $\begin{array}{l}\text { Channel width: } 50-75 \mu \mathrm{m} \text {, } \\
\text { wall thickness: } 50-75 \mu \mathrm{m}\end{array}$ & 200 cycle/min \\
\hline Rode et al. [72] & Laminate & Parallel passage sheets & Air separation & - & $\begin{array}{l}\text { Increased productivity and/or } \\
\text { recovery }\end{array}$ \\
\hline Patcas et al. [8] & Foam & Ceramic foams & Oxidation of $\mathrm{CO}$ & Foam 20, 45 PPI & $\begin{array}{l}\text { Better performance compared to } \\
\text { packed bed }\end{array}$ \\
\hline
\end{tabular}


Table 1 (Continued).

\begin{tabular}{|c|c|c|c|c|c|}
\hline Reference & Structure & Packing details & System & Experimental conditions & Results \\
\hline Bonaccorsi et al. [97] & Foam & $\begin{array}{l}\text { Copper foams coated with } 4 \mathrm{~A} \\
\text { zeolite }\end{array}$ & Heat pumps & $\begin{array}{l}\text { Pressures: } 10-65 \mathrm{mbar} \text {, } \\
\text { temperature: } 328-493 \mathrm{~K}\end{array}$ & High rate of water uptake \\
\hline Golden et al. [75] & Fabric structure & Multilayered adsorbent & $\begin{array}{l}\mathrm{H}_{2} \text { recovery by rapid } \\
\text { PSA }\end{array}$ & $\begin{array}{l}\text { Adsorbent surface } \\
\text { area }>500 \mathrm{~m}^{2} / \mathrm{g}\end{array}$ & $\mathrm{H}_{2}$ purity: $99.9 \% \mathrm{H}_{2}$ recovery: $70 \%$ \\
\hline Golden, et al. [6] & Fabric structure & $\begin{array}{l}\text { Self-supporting adsorbent } \\
\text { fabric }\end{array}$ & $\begin{array}{l}\mathrm{H}_{2} \text { production by rapid } \\
\text { PSA (RPSA) }\end{array}$ & $\begin{array}{l}\text { Feed temperature: } 0-100^{\circ} \mathrm{C} \\
\text { feed pressure: } 1.5-40 \mathrm{~atm}\end{array}$ & $\mathrm{H}_{2}$ purity: $99.9 \% \mathrm{H}_{2}$ recovery: $70 \%$ \\
\hline Bailey et al. [76] & Fabric structure & Charcoal cloth & Air purification & & $\begin{array}{l}\text { Lower resistance to gas flow, high } \\
\text { adsorptive capacity }\end{array}$ \\
\hline Sullivan et al. [78] & Fabric structure & Activated carbon cloth & Air purification & Electrothermal regeneration & Capture efficiency: 99.9\% \\
\hline Kim et al. [36] and Yamauchi et al. [61] & Paper honeycomb & $\begin{array}{l}\text { Corrugated paper rolled to } \\
\text { form honeycomb shaped } \\
\text { cylinder }\end{array}$ & VOC abatement & $\begin{array}{l}\text { VOC concentration: } \\
150-420 \mathrm{ppm} \text {, flow rate: } \\
150600 \mathrm{~L} / \mathrm{min}\end{array}$ & More than $95 \%$ VOC removal \\
\hline Matsukuma et al. [62,63] & Paper honeycomb & Rotary bed & $\mathrm{CO}_{2}$ recovery & $\begin{array}{l}\text { Adsorber: } 460 \mathrm{~mm} \text { diameter, } \\
480 \mathrm{~mm} \text { height }\end{array}$ & More than $80 \% \mathrm{CO}_{2}$ recovery \\
\hline Kodama et al. [60] & Honeycomb rotary adsorber & Sandwich arrangement & Desicant cooling & $\begin{array}{l}\text { Adsorber: } 0.3 \mathrm{~m} \text { diameter, } \\
0.2 \mathrm{~m} \text { height }\end{array}$ & $\begin{array}{l}\text { Dehumidifying performance was } \\
\text { much lower than that we expected }\end{array}$ \\
\hline Leedy et al. [96] & Honeycomb monolith & $\begin{array}{l}\text { Impregnated with alkaline or } \\
\text { caustic salts }\end{array}$ & $\mathrm{H}_{2} \mathrm{~S}$ removal & Impregnated with $10 \% \mathrm{Na}_{2} \mathrm{CO}_{3}$ & $\begin{array}{l}\text { Improved adsorption capacity, } \\
\text { shorter MTZ }\end{array}$ \\
\hline Ohrman et al. [92] & Monolith & $\begin{array}{l}\text { Cordierite monolith coated } \\
\text { with ZSM-5 film }\end{array}$ & P-xylene isomerisation & Seed-film method & $\begin{array}{l}\text { Films became less deactivated than } \\
\text { the films prepared on alumina } \\
\text { beads }\end{array}$ \\
\hline Matsuoka et al. [94] & Zeolite paper & Paper monolith & NOx removal VSA & $\begin{array}{l}\text { Pilot plant pressure: } 120 \mathrm{kPa} \\
\text { adsorption, } 5 \mathrm{kPa} \text { desorption, } \\
\text { temperature: } 298 \mathrm{~K}\end{array}$ & More than 95\% NOx recovery \\
\hline Mosca et al. [26] & Monolith, $400 \mathrm{cpsi}$ & $\begin{array}{l}\text { Cordierite monolith coated } \\
\text { with } \mathrm{NaX} \text { zeolite }\end{array}$ & $\mathrm{CO}_{2}$ capturing & $\begin{array}{l}\text { Pressure: } 1 \mathrm{~atm} \text {, temperature: } \\
\text { room temperature }\end{array}$ & 100 times lower pressure drop \\
\hline Belding et al. [50-53] & Adsorbent paper & $\begin{array}{l}\text { Corrugated paper or } \\
\text { honeycomb structure }\end{array}$ & Heat exchange wheel & - & $\begin{array}{l}\text { Adsorbing moisture from a humid } \\
\text { air stream }\end{array}$ \\
\hline
\end{tabular}


proportionally larger as the ratio of adsorbent volume to nonadsorbent void volume decreases. Typically, large low pressure PSA process vessels adsorb up to two magnitudes more gas on the adsorbent than exists in the void space. As the amount of adsorbent decreases (due to faster cycling), the proportion of void space to adsorbent volume increases and therefore increasingly work is done to simply compress and depress void space gas with no separation. Reductions in switching losses can only be achieved by higher adsorbent densities and careful engineering to minimize void space as well as investigation of alternate non-switching technologies, e.g. rotary valve systems.

\subsection{Role of pressure drop}

Pressure drop impacts system performance in several ways. The existence of a pressure profile in the axial direction in an adsorption process (both during adsorption and desorption) implies that not all of the adsorbent experiences the full pressure swing available to the system. This directly reduces working capacity, WC. The problem is especially acute for vacuum swing adsorption in which low vacuum pressures are needed for adsorbent regeneration, e.g. $\mathrm{CO}_{2} \mathrm{VSA}$ [1]. In this application, a vacuum pressure of $3 \mathrm{kPa}$ may be needed to produce sufficient $\mathrm{CO}_{2}$ recovery and throughput. Hence a pressure drop of just $1 \mathrm{kPa}$ in the bed during the vacuum step can reduce $\mathrm{CO}_{2}$ recovery by as much as $5 \%$. In addition to this effect, increased pressure drop increases energy consumption. One option to circumvent the high pressure drop problem of conventional packed beds without changing the type of adsorbent is to utilize radial bed adsorbers [2]. Radial beds produce lower pressure drop for the same mass flow rate due to the expanding radius in the direction of flow. Lower cycle time and higher throughputs without fluidization are possible, although their design is complex and costly.

To describe the role of system parameters contributing to pressure drop in a packed bed, the well known Ergun equation [3] is considered here:

$$
\frac{\Delta P}{L}=150 \frac{(1-\varepsilon)^{2}}{\varepsilon^{3}} \frac{\mu}{d_{p}{ }^{2}} U+1.75 \frac{(1-\varepsilon)}{\varepsilon^{3}} \frac{\rho}{d_{p}} U^{2}
$$

where $U$ is the superficial velocity, $\rho$ and $\mu$ are the density and viscosity of the gas, respectively, $d_{p}$ is the particle diameter and $\varepsilon$ is the bed voidage. Clearly decreasing void volume and particle size both increase pressure drop. Although decreasing void volume also increases pressure drop for structured adsorbents (not necessarily according to (2) however), it is easier in parallel channel adsorbents to control $\varepsilon$ to obtain satisfactory performance. In addition, the tortuosity of the channels in monolith or laminate structures is 1 , compared with 2-3 for a packed bed of granules. Therefore the pressure drop in a packed bed is larger than in a monolith structure for equal voidage. Furthermore, the system geometry in laminates and monoliths can be easily manipulated to achieve lower head loss. This is achieved by decreasing cell density or wall thickness in monoliths and increasing sheet spacing and decreasing wall thickness in laminates. Generally, parallel channels exhibit better performance with respect to pressure drop; however they must be carefully designed to avoid too much loss of adsorbent loading and large diffusion paths (wall thickness).

\subsection{Mass transfers characteristics}

Theoretical and experimental studies [4-8] have shown the influence of adsorbent structure on mass transfer kinetics which in turn influences the overall system efficiency. The separation performance may be degraded by dissipative effects of mass transfer resistance (internal and external) and axial dispersion. At higher gas velocities associated with higher cycle frequencies, the deleterious effects of mass transfer resistances typically increase, since in these conditions, the adsorption time scale becomes more comparable to cycle time. The diffusion time constant for the limiting resistance in adsorption systems is of order $\mathcal{L}^{2} / \mathcal{D}$ where $\mathcal{L}$ is the limiting length parameter and $\mathcal{D}$ the corresponding diffusivity. For pellets, $\mathcal{L}$ is the pellet radius and $\mathcal{D}$, the "effective" diffusivity. In conventional packed bed processes, with cycle times of the order of hours or even minutes, the timescale for adsorption into/out of the pellets is approximately 5-100 times shorter than the residence time and hence mass transfer resistance is not dominant. This picture changes dramatically when rapid cycles are used. If interstitial velocities are 10-100 times higher, then the time scale for adsorption becomes comparable to, or even greater than the residence time leading to immediate breakthrough of the gas and unacceptable operation. To reduce the timescale for adsorption, smaller particles can be used, however, the resultant pressure drop and low mechanical stability rapidly becomes unmanageable. Moreover, with increasing space velocity, conventional packed bed adsorbents can be fluidized. The advantages of a rigid adsorbent structure are therefore readily apparent.

Some adsorption process models developed are based on local equilibrium, i.e. ignore the mass transfer resistances in the system. In reality, those resistances are not always negligible and must be taken into account for more reliable prediction of system performance. The overall mass transfer coefficient, $k$, for systems with linear isotherms obeying the linear driving force model can be evaluated through the relationship [9]

$\frac{1}{k K}=\frac{R_{p}}{3 k_{f}}+\frac{R_{p}^{2}}{15 \varepsilon_{p} D_{p}}+\frac{r_{c}^{2}}{15 K D_{c}}+\left(\frac{1-\varepsilon}{\varepsilon}\right) \frac{D_{L}}{v^{2}}$

where $K$ is the equilibrium constant, $k_{f}$ is the external film coefficient, $R_{p}$ and $r_{c}$ are particle and crystal radii, respectively, $D_{p}$ and $D_{c}$ are pore and intracrystalline diffusivity, respectively, $D_{L}$ is axial dispersion and $v$ is velocity. The relative importance of internal and external resistances is expressed by the Biot number $k_{f} L / D$ where $L$ is a characteristic dimension (particle diameter) and $D$ the internal diffusion coefficient. The mass transfer Biot number for packed beds for most applications is in the range of 5-500 and hence the major resistance for mass transfer is within the particle [10]. Generally speaking, micropore diffusion resistance dominates over film and macropore resistances if

$\frac{D_{p} / R_{p}^{2}}{D_{c} / r_{c}^{2}} \gg 1+\left(\frac{1-\varepsilon}{\varepsilon}\right) K$ and $\frac{5 D_{p}}{k R_{p}} \ll 1$

The opposite situation holds for macropore diffusion. In pelleted systems and foam structures, the external film resistance seldom plays a role in overall mass transfer and is usually neglected. According to Patcas et al. [8], the external mass transfer coefficient of foam structures is somewhat between those of monoliths and packed beds. Typically, the mass transfer coefficient of foams would increase by increasing the pore count at constant hydrodynamic conditions due to enhanced surface area available for adsorption. In the case of laminates and monoliths, however, we expect film resistance to be very important, even governing, depending on channel and wall thickness dimensions. Larger film coefficients can be obtained by smaller channel diameters and sheet spacing. Unfortunately, the dependence of the film coefficient on Reynolds number is quite weak as shown below. Higher velocities are therefore not a practical way of achieving better mass transfer. We expect laminar flow to prevail in the channels for all typical cycle times. The film resistance is comparable to the pore diffusion resistance in this situation especially when the laminate or monolith walls are very thin and internal mass transfer is very rapid. 
The appropriate dimensionless group characterising film diffusion is the Sherwood Number, Sh. For pelleted systems the Wakao-Funazkri equation [11] is typically used to estimate $k_{f}$

$S h=2+1.1 R e^{0.6} S c^{0.33}$

For monolithic and laminate structures, Hawthorn's equation [12] for laminar flow is employed

$S h=\frac{d k_{f}}{D_{m}}=A\left(1+0.139 \operatorname{ReSc} \frac{d_{h}}{L}\right)^{0.81}$

where the parameter $A$ is 3.6 for circular channels, 2.35 for triangular channels and 2.95 for square channels. $D_{m}, d_{h}$ and $L$ are molecular diffusion coefficients, channel hydraulic mean diameter and column length, respectively. Typically, $d / L$ is very small since channels are of diameter $1 \mathrm{~mm}$ and length $100 \mathrm{~mm}$ while Re is usually small $(<500)$. A generalised correlation proposed by Groppi et al. [13] is appropriate to describe the external film mass transfer coefficient in foam structures

$S h=0.91 R e^{0.43} S c^{0.33}$

subject to the constraint

$15<\operatorname{Re}<200$

It is clear therefore that external film diffusion which is typically neglected for particulates may be important for adsorbent structures and should be considered when modelling and designing these systems. A more detailed assessment of the impact of external film resistance has recently been conducted by Rezaei and Webley [14].

The contribution of axial dispersion to $k$ for pellets, is usually small (similar to external diffusion) and can justifiably be neglected. The plug flow assumption is therefore adequate. Note however that very small particles $(<1.0 \mathrm{~mm})$ have significantly increased axial dispersion and $D_{L} / v^{2}$ may become comparable to pore diffusion resistance and indicates that for small diameter pellets, gains in kinetic effects from reducing particle size can be rapidly offset by increased axial dispersion. In monoliths, axial dispersion is much more dependent on channel diameter and flow rate. For laminates, resistances in the porous material and external film are far greater than axial dispersion in the gas phase. Axial dispersion in a packed bed is correlated in terms of the Peclet number $\left(P e=U d / D_{L}\right)$, and can be obtained from

$\frac{\varepsilon_{b} D_{L}}{D_{m}}=20+0.5 \operatorname{ReSc}$

where $D_{m}$ is the molecular diffusion coefficient and $d$ is particle diameter. The same expression is used for foam structures. In laminar flow, axial dispersion in monolithic structures can be calculated from Taylor's [15] analysis

$P e=\frac{U d}{D_{L}} \approx 192 \frac{D_{m}}{U d}$

For laminates, a similar approach holds as with monoliths. In turbulent flow, Taylor analysis gives:

$P e=\frac{0.28}{\sqrt{f}}, \quad f=0.046 R e^{-0.2}$

For this case, the extent of axial dispersion is greater but still significantly less than the other factors causing broadening of the mass transfer zone. In fact, more detailed analysis reveals that axial dispersion is usually negligible even in monolithic and laminate structures [14]. Of course maldistribution and channelling are more likely in monolith systems and laminates and require attention to detail in the fabrication process.
It should be noted that the binder in adsorbent structures may influence the role of mass transfer. In certain adsorptive applications such as dehumidification processes wherein the diffusivity of the adsorbate molecule (water) through the binder layer is high enough to reach the adsorbent particles, the binder material does not degrade the overall kinetics of the process. In contrast, in several adsorptive processes such as air separation application, the binder serves as a kinetic barrier to adsorbate molecules from reaching the adsorbent particle. The detailed pore engineering required for efficient mass transfer at the micro- and meso-scopic scale applies to all adsorbent structures.

\subsection{Thermal management}

As mentioned earlier, pressure swing systems are affected by the thermal swing accompanying the adsorption/desorption process. As a first estimate, the temperature swing at a point in the bed is given by

$\Delta T=\frac{W C * Q_{a d s}}{C_{S}}$

where $W C$ is the working capacity, $Q_{a d s}$ is the heat of adsorption and $C_{s}$ is the solid specific heat $(\mathrm{kJ} / \mathrm{kg})$. In turn, the temperature swing affects the adsorption and desorption detrimentally, reducing capacity on adsorption and increasing it on desorption. To reduce the effect of this temperature swing several approaches have been attempted including insertion of heat transfer devices into the packed bed [16], or use of metallic compounds or phase change materials to either increase $C_{s}$ or absorb the heat of adsorption [17]. These approaches have met with limited success since in the case of pellets having a size more than several micrometers, there is a temperature gradient between the surface and the inner part of the particle during adsorption and desorption due to poor thermal conductivity of the adsorbent material. Therefore it is difficult to obtain a uniform temperature across the particle regardless of external heat transfer devices.

Adsorbents in the form of laminates, monoliths, cloths and foams can positively influence the thermal behaviour of an adsorber bed by selecting a suitable support material with a favourable thermal conductivity. Consequently, the thermal properties of the system can be carefully engineered. In the case of monoliths, foams and laminates, a macropore wall structure can facilitate the dissipation of heat and consequently more nearly achieve a uniform temperature distribution across the adsorbent. With regard to laminate structures, metallic supports exhibit favourable thermal properties with high thermal conductivity and heat capacity. Care must be taken however to avoid relative stresses induced in the system during cyclic heating and cooling which may result in detachment of the adsorbent material from the support.

Foamed adsorbents offer a unique structure of high porosity (75-90\%) and tortuosity, and hence we expect a more uniform temperature distribution in the adsorbent. This is due to improved turbulence and an inherent structure which means that heat can be transported not only by conduction, but other mechanisms such as convection and even radiation. This a fertile area for future research since not only can adsorbent structure manage heat more effectively in a passive mode, but they may in fact offer opportunities for "active" thermal management (see Section 3.6).

\subsection{Trade-off of properties}

The design of adsorbent structures involves, inevitably a tradeoff between a number of parameters which govern the overall adsorbent performance. Adsorbents with high working capacity and fast kinetics are favoured for cyclic separation processes, however these requirements can only be met at ideal conditions. 
External surface area per unit volume of adsorbent is one of the most important characteristics governing the performance of adsorbents but higher surface area is usually associated with lower adsorbent density. For laminate, cloth and monolith structures, in order to maintain a sufficient surface area and hence improved kinetic properties, the wall thickness and spacing should be kept small. Thinner wall thickness means shorter diffusion path but on the other hand, lower adsorbent loading associated with thinner walls will result in insufficient adsorbent density [14]. The same argument is valid for adsorbent voidage. High voidage may be associated with faster kinetics, however, the bed density is low which gives rise to lower working capacity. Small spacing between adjacent sheets or small channels increases the pressure drop as well. In the case of beads there is always a trade-off between pressure drop and mass/heat transport characteristics, smaller pellets display clearly high surface area and mass/heat kinetics, while the system pressure drop is dramatically increased.

Such trade-off behaviours should always take into consideration when dealing with adsorbent structure. In this regard, a formal optimization approach could be employed by conducting appropriate simulations or experiments to identify the optimum conditions for a particular application. A general procedure to illustrate this interplay of features is provided below in Section 3.7.

\section{Alternate adsorbent configurations}

A large variety of structured adsorbents have been studied and commercialized over the last 20 years. Table 1 provides a summary of these reported structures together with details of the experiments and key experimental results. The structures can be categorized as monoliths (including honeycomb topologies), laminates, foams, fabric structures and "other" structures.

\subsection{Monolithic adsorbents}

In recent years, monolithic adsorbents have received considerable attention for use in adsorption systems [18]. Monoliths are structured supports composed of parallel channels with a variety of cross-sectional shapes. They have been widely used as a catalyst support in various applications including catalytic combustion, biochemical and electrochemical reactors, automotive catalytic convertors, etc. $[18,19]$. The use of monoliths in adsorption process is rather new compared to its applications in the catalytic field [20-22]. The characteristic difference between adsorptive and catalytic monoliths stems from the need for sorption capacity in the former. Hence monoliths for adsorption are often entirely comprised of adsorbent (or at least highly filled) while catalytic monoliths usually rely on a wash coat of active catalyst on a monolithic support.

Early attempts in the use of monolithic adsorbent structures for separation process were mostly related to elimination of VOCs from air $[21,23]$. MAST carbon, a specialist developer of activated carbon produces a variety of activated carbon monoliths for a range of applications including (but not limited to) VOC removal. Li et al. [24] examined the technical feasibility of $5 \mathrm{~A}$ zeolite monolith (containing 25\% Na-bentonite) for the production of oxygen-enriched air. They compared their results to a packed bed of commercial pellets and showed while the separation performance of the monoliths was inferior to the pellets, the pressure drop in the monolith system was almost 3-5 times lower than the one in the packed bed, resulting in a 3-5 times faster pressurization time.

Although the unique structure of monoliths (continuous body with identical channels) significantly reduces the common problems of conventional adsorbents (i.e. fluidization, high pressure drop, etc.), these structures may very low loading of active adsor- bent material. In addition, not all the adsorbent material present in the skeleton of the monolith wall is accessible to the adsorbate molecules passing through the channels. The active adsorbent material may be directly extruded in the form of a structured monolith (commonly done for carbon monoliths in which case the entire monolith is active adsorbent) or an active film may be grown on the monolithic structures by various methods, namely, dip-coating, wash-coating, and slip-coating [25]. Mosca et al. [26] have shown how films of NaX zeolite may be deposited on cordierite monolith supports. In order for monolithic adsorbents to meet the mass transfer requirements for efficient performance, both channel and wall thickness should be as small as possible [27]. It is known that monoliths with higher cell densities would give proportionally better performance because of their higher geometrical surface area and solid loading; however, the improvement gained by higher density must be weighed against the added cost of their manufacturing, since the manufacturing of such structures is complex and difficult. Furthermore, monoliths at such high density (several hundred to over one thousand cpsi) with a large loading capacity of active adsorbent are not available yet in commercial quantities. An interesting and dramatic demonstration of the effectiveness of ultra-high cell density monoliths was provided by the work of $\mathrm{Li}$ et al. [28] in which a cuttlebone was used as a biomorphic template to produce a monolith of NaX with 16,000 cells per square inch. These materials showed excellent mass transfer properties and still exhibited lower pressure drop than a packed bed.

The geometric parameters of monoliths which influence the processing requirements are defined in terms of cell density, cell spacing or wall thickness. The cell density of monoliths is defined as the number of cells per unit of cross-sectional area and expressed as cells per square inch (cpsi). As discussed earlier, monoliths provide lower pressure drop per unit length of the bed than a packed bed. Given constant gas viscosity, monolith length, and open frontal area (OFA), the pressure drop of monolith adsorbents increases with increasing cell density. On the other hand, given a constant cell density, the pressure drop decreases with decreasing wall thickness. Thus monoliths are one of the most efficient methods available to pack high adsorbent surface area into a fixed volume while still maintaining low pressure drop.

Monoliths have two major resistances to mass transfer; external film resistance, and pore diffusion within the walls. The characteristic diffusion length can be shortened by employing a thinner adsorbent wall. Unfortunately, the residence time in the monolith is likely to be much shorter than in a packed bed so that the timescales of diffusion and transport through the channels may be comparable. The low pressure drop of monoliths and laminates must be exploited by using long beds to give large gas residence times. High cell densities are favoured since these produce high adsorbent loading and short diffusion lengths.

Meyers and Liapis $[29,30]$ have employed pore network theory to determine in an a priori manner, the mass transfer and pressure drop characteristics of monoliths and in columns packed with porous particles. The outcome of their microscopic model was then employed in a dynamic macroscopic model to describe the dynamic behaviour of chromatographic columns. In another study conducted by Liapis et al. [31], the dynamic behaviour of monolith adsorbents in a chromatographic column was evaluated through mathematical modelling. Their result indicated remarkable benefits of monolithic adsorbents over spherical particles if a suitable monolith (large through pores and small-sized skeleton) with controllable dimension is employed.

In another study, the adsorption kinetics and diffusion of $\mathrm{CO}_{2}$ in carbon based monoliths was studied using the zero length column (ZLC) method by Brandani et al. [32]. These authors showed that the dispersion in the monoliths is mainly controlled by mass transfer resistance rather than axial mixing. Recently, Mosca et 
al. [26] have used structured adsorbents in the form of thin zeolite films supported on cordierite monoliths for $\mathrm{CO}_{2}$ capture in PSA systems. The pressure drop was 45 times lower than a comparable packed bed although the adsorption capacity of the new configuration adsorbents was 67 times lower than conventional beads. Their results suggest the potential of monolith structured adsorbents as a competitive alternative to traditionally used packed beds in PSA processes providing a high cell density can be used.

Activated carbon monoliths such as those produced by MAST carbon, are another class of adsorbents which offer great potential for use in various applications such as electric swing adsorption (ESA) and military filtration applications. The monoliths are typically synthesized from a phenolic resin precursor followed by carbonization step which offers high surface area available for adsorption [33]. Due to inherent electrical conductivity of activated carbon, rapid thermal swing operation can be achieved by regeneration of the monolith through electrical heating. In contract to hot purge gas, this method will achieve far faster cycles. In addition, activated carbon monoliths are self-supporting and hence are virtually $100 \%$ active material. This advantage offered by carbon monoliths makes them suitable candidates for electrical swing adsorption (ESA) processes. A more detailed discussion of ESA devices is presented in Section 3.6.

A number of studies have reported monolithic adsorbents for the removal of volatile organic compounds (VOCs) from air [23,34-38]. Shah et al. [39] studied the removal of volatile organic compounds (VOCs) from air using monoliths and performed simulations for comparing the performance of their novel adsorbents with a packed bed of pellets. In another study Lee et al. [40] showed that the adsorptive performance of hydrophobic zeolite monoliths in the removal of VOCs from air improves by increasing the cell density and reducing wall thickness.

Patton et al. [7] observed that by optimizing the design of monolithic structures such as appropriate wall thickness, channel width and shape, it would be possible to improve the separation performance of monoliths. They further suggest the use of regular hexagonal channels, for efficient internal mass transfer performance. The authors then evaluated the performance of hexagonal monoliths with a wall thickness of $0.4 \mathrm{~mm}$ and a channel dimension of $0.6 \mathrm{~mm}$ for the removal of VOCs from air and showed that the internal mass transfer performance of these adsorbents are comparable with a typical packed bed containing $1 \mathrm{~mm}$ pellets.

Grande et al. [41] demonstrated the behaviour of zeolite 4A honeycomb monolith for the adsorption of propane and propylene at different pressures and temperatures. Adsorption equilibrium data of both gases were reported to be identical to commercial extrudates, while the kinetic parameters were three orders of magnitude smaller than extrudates. In other studies performed by Zabka et al. $[42,43]$ the main focus was devoted to the utilization of silicabased monoliths in HPLC columns and the equilibrium and kinetics of adsorption was examined by taking into account Darcy's law and HETP concepts.

Cutler et al. [44] discloses the use of honeycomb monolithic adsorbents for fuel desulphurization process. The authors further recommend the utilization of such adsorbers in fuel reforming apparatus for generating hydrogen fuel for hydrogen-powered fuel cells, or in fuel delivery systems for supplying low-sulphur fuel to combustion engines, or in other systems supporting combustion processes requiring the use of low-sulphur fuel. Adsorption of $\mathrm{CO}_{2}, \mathrm{CH}_{4}$ and $\mathrm{N}_{2}$ in activated carbon honeycomb monoliths was performed by Ribeiro et al. [45]. This investigation aimed at the generation of bio-methane from renewable fuels. The authors conducted mathematical modelling for further evaluation of adsorption performance of honeycomb monoliths. A recently published patent by Jain et al. [46] reports the operation of rapid
PSA systems for air separation processes for a cycle time of $35 \mathrm{~s}$ using monolith adsorbents.

Desulphurization process can be performed using adsorbents or catalysts in different forms including pellets/beads, foams or monoliths. He et al. [47] studied the development of high surface area structured monolith adsorbents for sulphur removal. These honeycomb sulphur traps were fabricated by extruding commercially available sulphur removal catalysts such as zinc based materials into monolithic honeycombs, however, no information regarding the application of this honeycomb sulphur adsorbent was provided.

Monolithic adsorbents are found to be suitable for use in NOx adsorbers. In these cases, the active adsorbent materials such as zeolites, silicas or alkali/alkaline earth metal oxides are washcoated on the monolithic structure. Kaboord et al. [48] disclosed pollution control devices, especially adsorbent and catalyst beds for diesel engines using monolith structures.

Jale et al. [49] disclosed the use of alkali or alkaline metal salts in preparing zeolite containing adsorbent sheets, their preparation into adsorbent monoliths and their subsequent use in air separation process. Based on the author's claims, the prepared monolith adsorbent exhibits improved nitrogen capacity (around $0.6 \mathrm{mmol} / \mathrm{g}$ by addition of $\mathrm{LiOH}$ to the sheet) and nitrogen/oxygen selectivity (9.1 at 300 mbar) in air separation process via either PSA or VSA.

The rapid heating and cooling features of monolithic and thin walled zeolite systems make them ideally suited to TSA applications. One such application is dehumidification of air [50-54]. In these applications, monoliths are fabricated into large rotary wheels, permitting alternate adsorption and desorption to occur at different parts of the wheel as it is rotated. For instance, Belding et al. [50], describe the employment of Y-zeolite in the fabrication of a desiccant wheel to provide a body which readily adsorbs moisture contained in ambient air. They further showed through experiments that the zeolite wheel is very efficient in water removal with a capacity of 5.41 tons and a coefficient of performance of 0.92 [53].

The potential application of adsorbent polymer monoliths in particular, zeolite 4A-polyamide adsorbent, in rapid PSA for the adsorption of water vapour was evaluated by Gorbach et al. [55]. According to their results, although the adsorption capacity of the polymeric adsorbents was found to be the same as pellets, the mass transfer kinetics was enhanced substantially. The advantage of polymeric monoliths over conventional ceramic monoliths could be in the manufacturing step, which is simple and avoids energy-intensive high temperature treatment steps, although the after-treatment step (creating a secondary pore structure) is an energy demanding step.

Although many studies have been undertaken to evaluate the mass transfer and pressure drop characteristics of monoliths in adsorption applications, the effect of thermal management and adsorbent loading in adsorptive efficiency has been scarcely discussed. Future work should carefully consider the potential enhancement in performance by examining the options of thermal management for monolithic structures.

The introduction of thermal swing honeycomb rotor adsorbers into the market in 1980s for VOC removal opened a new path toward development of air treatment process and stimulated researchers to study this area. This developed technology utilizes the adsorbent material in the form of a honeycomb or monolith configuration rather than particles. The employment of the adsorbent in these configurations (honeycomb or monoliths) gives rise to a rapid response to temperature swing in the regeneration step. Initially, activated carbon was chosen to act as adsorbent material, however, soon, it was replaced by zeolite type adsorbents (high silica adsorbents) in order to avoid the possibility of adsorbent ignition during thermal regeneration by hot air. 
Zeolite paper honeycomb structures have found several applications in adsorption processes mainly VOC removal and air treatment by TSA apparatus. These adsorbents are usually made by impregnation of ceramic papers and corrugating the sheets in order to create the honeycomb structure [21,56-60]. In the study conducted by Kim et al. [36] zeolite paper in the form of honeycomb rotors was employed in the removal of trace amount of VOCs. Their honeycomb adsorbent showed a remarkable efficiency for removing toluene, MEK and cyclohexanone. In another recent study by Yamauchi et al. [61], a zeolite honeycomb rotor adsorbent was applied to the VOC abatement systems operating with TSA. These authors showed that the VOC removal efficiency depends mainly on variables such as rotation speed, gas flow rate, regeneration temperature. By operating at optimum condition based on these variables, it is possible to achieve a high performance with more than 95\% VOC elimination from the feed gas. Although the honeycomb adsorbers were first employed for elimination of VOCs and other pollutants, recently, some researchers have reported the application of this type of adsorbents for $\mathrm{CO}_{2}$ recovery [62]. Matsukuma et al. [63] showed through pilot plant experiments that the $\mathrm{CO}_{2}$ recovery in rotary adsorption towers having an inner diameter of $460 \mathrm{~mm}$ and adsorbent height of $480 \mathrm{~mm}$ could attain more than $80 \%$.

Another application of multi-pass honeycomb rotary adsorbers is in desiccant cooling systems with a sandwich arrangement of honeycomb shaped adsorbed blocks and aluminium passages [60]. In terms of thermal management, this structure offers advantages in terms of operating at semi-isothermal condition. The authors suggest the direct regeneration of this system by hot water heating instead of air.

\subsection{Laminate adsorbents}

Laminate structures can be considered a simpler form of monoliths in which the channels are replaced by 1D slits. As with monoliths, they can potentially exhibit significantly better performance than a packed bed. The practical difficulties involved in reproducibly making such structures are not trivial however. The tolerances between sheets must be tight $(<5 \%)$ to avoid maldistribution. This requires that the spacing must be maintained to within less than $0.01 \mathrm{~mm}$ generally speaking. As a result of this difficult manufacturing process, the use of laminate adsorbents in separation processes is not common. There are few published patents which describe the use of adsorbent materials in the form of laminate sheets in adsorptive gas separation applications [6,64-66].

Like monoliths, laminate adsorbents suffer from the problem of low adsorbent density due to several factors. A binder is usually present in the adsorbent matrix in addition to the presence of an external support. These non-adsorbent components directly reduce the volume loading of the adsorbent. This is in contrast to fabrics or self-supporting adsorbents where the structure itself would be able to compensate the problem of low adsorbent density. Laminate sheets can be packed into corrugated layers to increase adsorbent loading (and surface area) [36].

In laminate structures, the pressure drop per unit length is controlled mainly by altering the space between adjacent sheets. Like monolithic structures, thin sheets with small spacing not only increase pressure drop but also increase adsorbent loading and decrease mass transfer resistance. To achieve a practical configuration, some spacing technology is needed to ensure uniform channel width. These spacing devices can be manufactured by different methods, such as corrugating the laminates or making ridges on the sheets. The spaces between adjacent layers could be also created using external spacing devices such as mesh or grid. Care must be taken to ensure the spacer technology does not significantly con- tribute to higher pressure drop nor obstruct the gas flow through the adsorbent.

In 1992, Keefer [67] studied the operation of gas separation by PSA at high cycle frequencies using laminated parallel passage adsorbers. The adsorbent sheets were layered as a stack of flat sheets with channel width between adjacent sheets ranging from 15 to $75 \mu \mathrm{m}$. They showed that the attainable cycle frequency of these laminate sheet configurations is superior by almost an order of magnitude to that attainable in a packed bed, while the bed length could be reduced by a similar factor. They further employed their structured adsorbents for extraction of trace levels of $\mathrm{H}_{2}$ isotopes from helium in which the $\mathrm{H}_{2}$ recovery was shown to be $100 \%$ with $34 \%$ purity. Maurer [68] described the application of a spirally wound adsorbent in TSA systems for gas purification. The adsorbent layers contain adsorbent particles and the layers are separated by screens located between them. Ruthven and Thaeron [4] performed some theoretical and experimental studies on the application of a parallel passage adsorbent (coated with activated carbon fiber) for separation of $\mathrm{CO}_{2}$ and $\mathrm{N}_{2}$. Their results revealed that such adsorbent configurations are well suited to a dual piston rapid PSA system, and offer a combination of low pressure drop and a large number of theoretical stages for applications like $\mathrm{CO}_{2}$ removal from stack gases. Another interesting outcome of this investigation was that macropore diffusion is a dominant mass transfer resistance in ACF sheets. Furthermore, numerical simulation of such parallel passage contactors used in piston-driven PSA was performed in another study [69]. The model developed could efficiently predict the pressure dynamics of parallel-passage piston-driven PSA.

In more recent published patents $[64,70]$ Keefer and co-workers illustrate the utilization of adsorbent laminate structures at ultra rapid PSA systems operating at cyclic frequency of 100 cycle per minute (corresponding to a cycle time of $0.6 \mathrm{~s}$ ) while the cycle time of conventional PSA devices for gas separation processes is on the order of several minutes. Such laminate adsorbents could be created in different configurations such as rectangular, spiral-wound or annular stack. Moreover, a support or a reinforcement material is required in their fabrication.

Keefer et al. [66] discloses methods of fabricating zeolite adsorbent laminate structures with various sheet supports such as metal foils, woven wire mesh, woven glass fiber cloth and nonwoven fiber glass scrims for the use in PSA systems. The adsorbent laminates coated with X-zeolites were then used in oxygen enrichment PSA with cycle frequencies up to 200 cycles per minutes. The adsorbent laminates had a channel width of $50-75 \mu \mathrm{m}$ with adsorbent thickness of 50-75 $\mu \mathrm{m}$ on both sides of the sheets. Although methods for forming adsorbent laminate structures particularly for use in PSA devices have been addressed in detail, no report on the utilization of such structures in real processes has been reported.

Laminate adsorbent structures have been described by Sawad et al. [71]. The authors teach the fabrication of high density adsorbent sheets by different technologies. Based on the patent claims, it would be possible to couple the benefits of metallic monoliths (i.e. heat transfer characteristics) and those self-supporting adsorbent sheets through impregnating sheets by materials with high heat transport rate.

Rode et al. [72] illustrated the application of improved adsorbent sheet-based parallel passage structures for PSA, TSA and partial PSA devices. According to this patent, the adsorbent can be constructed by adhering a suitable adsorbent to a support sheet, mesh or grid on one or both sides of the sheet. These sheet layers may include a binder to immobilize the adsorbent particles or fibrous materials for reinforcement of structure. These authors examined the performance of laminate sheets by employing them for air, $\mathrm{CH}_{4}-\mathrm{N}_{2}$ and $\mathrm{CH}_{4}-\mathrm{CO}_{2}$ separation systems. This patent reports the utilization of such configurations not only in kinetic-controlling processes but also in different adsorptive separation systems by incorporat- 
ing suitable adsorbent materials. In the case of air separation over a modified 4A zeolite in the form of adsorbent laminates, their results showed that cycle frequency can be intensified by a factor of 4 , when the zeolite crystal diameter is reduced by a factor of 4. Alternatively, the adsorbent structure may use zeolite crystals of $1 \mu \mathrm{m}$ diameter to achieve a 16 -fold intensification (increasing cycle frequency toward 160 cycles/min), while retaining approximately equal kinetic selectivity and thus separation performance. Moreover, based on the author's claims, for separation of carbon dioxide from methane, the ideal kinetic-controlled adsorptive selectivity could be as high as around 100 which may be very favourable for effective separation.

\subsection{Foam structures}

Ceramic foams have many attractive features as catalyst supports, however, their utilization in adsorptive gas separation applications is scarce. These types of adsorbents may have substantial benefits over other adsorbent configurations. They offer high geometric surface area resulting in an increase in the rate of external mass transfer and due to their inherent large porosity these structures are capable of maintaining a lower pressure drop than a packed bed of pellets/beads [73]. However, it is argued that such structures may not be suitable candidates in several cyclic processes such as PSA or partial PSA devices because of the adsorbent's high tortuosity and porosity which decrease separation performance.

Due to the inherent high porosity of foam adsorbents, the amount of active material may not be adequate to exhibit the same volume activity as a packed bed of pellets, however, this problem could be solved through adjusting the amount of adsorbent coating on the structure of the foam. As with monolith adsorbents, the flow friction and hence the pressure drop is decreased due to the larger flow channels and presence of large number of voids which allows the radial mixing of flow. This is the advantage (high bed porosity) of foam adsorbents over monolithic structures in which laminar flow does not allow radial mixing. Typically, higher voidage in the bed is favoured for operation at high velocities (i.e. high cycle frequency in cyclic operations) where pressure drop becomes crucial.

More recently, Patcas et al. [8] have performed an experimental comparison of catalysts with different carriers, namely, honeycomb monoliths, ceramic foams and spherical particles based on their pressure drop and mass and heat transfer characteristics in the oxidation of carbon monoxide. Their result showed that the performance of foam catalysts in terms of combined high mass transfer and low pressure drop was superior to particles and inferior to that honeycomb structures.

There has been extensive research on the preparation of zeolite foams using polymeric templates [71,74], but in spite of the promising advantages offered by foam structures, their employment in gas separation processes has not been studied yet. According to Yoon et al. [74], since there is no blocking problem owing to a binding agent and since zeolite is formed in the form of a thin layer in the foam even without any separate support, gas can freely move inside the zeolite foam having various outer shapes and thus the zeolite usage efficiency is substantially increased to nearly $100 \%$. Moreover, due to the presence of macropores which are spatially communicated with each other and are large enough for molecules to freely enter and leave, the pressure drop could be substantially reduced in adsorption processes.

\subsection{Fabric structures}

Adsorbent fabrics present advantageous features for gas separation application. Due to the self-supporting nature of these configurations, they can potentially provide high adsorbent loadings while simultaneously providing very rapid mass transfer through the thin fibers of which the fabric is composed. Adsorbent fabric can be fabricated into various configurations in such a way that it still maintains the benefits of the fabric. The preferred configurations are parallel sheets and spiral-wound structures. Additional advantages offered by flexible adsorbent fabrics are lower attrition rates and higher mechanical strength. There is often no requirement for external support or spacers [75]. The heat transport characteristics of fabric adsorbents could be enhanced by modifying the materials present in the structure through employing materials with high thermal conductivity (by coating or impregnation techniques or weaving). Self-supporting cloths offer a lower resistance to gas flow and give rise to a lower pressure drop in the bed and of course eliminate fluidization issues.

The use of adsorbent fabrics in adsorption processes was first reported in the early 1980s when Bailey et al. [76] described the application of charcoal cloth configuration in adsorptive filters for air purification process. This patent claims that such cloth form adsorbents offer an appreciable adsorptive capacity and a much lower resistance to gas flow when compared to conventional pellets/beads. These charcoal cloths could be preferentially positioned parallel to the direction of gas flow for better performance.

Golden et al. [6] reports the use of adsorbent fabrics with average pore diameter from 12 to $15 \AA$ in rapid PSA systems for $\mathrm{CO}_{2}$ capturing and $\mathrm{H}_{2}$ recovery. They found that these configurations are particularly suitable at shorter cycle times where mass transfer characteristics play a key role in separation. Employment of fabric adsorbents at longer cycle times where separation is performed based on equilibrium, does not give rise to any advantage over packed beds of pellets. Later, Golden et al. [75] reported data for the capture of $\mathrm{CO}_{2}$ and $\mathrm{H}_{2}$ recovery by rapid PSA and compared the results with monolithic and granules geometries. They claim a hydrogen recovery of at least $70 \%$ and a productivity of $99.9 \%$. In the case of $\mathrm{CO}_{2}$ adsorption using self-supported fabrics, a $\mathrm{CO}_{2}$ mass transfer coefficient of at least $0.5 \mathrm{~s}^{-1}$ can be obtained which corresponds to a larger mass transfer rate than that attainable in a packed bed.

Sawad et al. [71] demonstrated coating activated carbon powder onto a fabric, cloth or felt made from activated carbon fibers. According to the authors' claims, such adsorbent structures have the advantage that the substrate itself is an active adsorbent material which leads to a higher density adsorbent compared to the same system using an inert or non-adsorbent support.

By using an organic binder system, an activated carbon-coated activated carbon fabric, cloth, or felt may be treated under the appropriate conditions (including high temperature pyrolysis and a steam- or $\mathrm{CO}_{2}$-activation stage) to convert the binder to active adsorbent. Using either or both of the above inventive modifications, the resulting adsorbent sheet possesses a high adsorbent density because a greater portion of the sheet structure may actively adsorb gases compared to systems where the binder and/or substrate are inert toward the desired adsorption process [71].

In the case of electrothermal desorption of adsorbents, Petkovska et al. [77] employed a bed with layers of activated carbon cloths in TSA process. A few years later, Sullivan et al. [78] used the same adsorbent configuration for removing hazardous air pollutants such as MEK, with a capture efficiency of more than $99.9 \%$ by mass. The adsorbent cloths were used in annular-cartridge configuration with the advantage of rapid electrothermal regeneration as well as low pressure drop. In another study Baudu et al. [79] applied the principle of thermal regeneration by Joule effect to a bed of activated charcoal cloth/or grains, for air treatment application.

As with fabric adsorbents, very little research has been performed with respect to thermal management or adsorbent loading considerations. Based on the unique feature of such adsorbents and 
noticeable benefits gained by utilizing them in advanced adsorptive separation processes, there is a large opportunity to exploit their features for thermal management.

\subsection{Other structures}

In the case of traditional pellets used in adsorptive gas separation, recent advances have been achieved for fabrication of binderless pellets by converting the binder material to an active adsorbent. This dense packing technology tends to maximize the density of active adsorbent material. Attempts have been made to improve the fabrication process of beads/pellets; synthesizing of particles with controllable physical properties and well-ordered structures with uniform pore size distribution are among them. However, the most important drawback of particles configurations (high pressure drop) remains a large challenge which motivates the application of other structures.

The film growing method is another widely used technology for improving the adsorbent performance by increasing the active material loading [80-90]. Nikolajsen et al. [91] developed a structured sintered metal fiber plate covering a thin film of MFI-type zeolite for adsorption applications. This configuration was shown to be an efficient adsorbent in VOC removal. Ohrman et al. [92] grew well-defined ZSM-5 films on $400 \mathrm{cpsi}$ cordierite monoliths using the seed-film method. They further tested their structured catalysts for P-xylene isomerisation. In another approach, Perdana et al. [93] reported the modelling of cordierite monoliths coated with a thin film of NaZSM-5, for NOx adsorption application. Matsuoka et al. [94] describes the bench and pilot scale NOx removal by adsorption process using VSA apparatus. The recovery of NOx from the denitrator was reported to be more than $95 \%$.

Barrett et al. [95] fabricated adsorbent beads with higher mass transfer rates than ordinary pellets. The method employed for making these pellets involves the steps of low pressure extrusion and spherization. Although a detailed description of manufacturing steps was provided, the potential application of these improved pellets was not discussed.

Recently Leedy et al. [96], employed adsorbent honeycomb monoliths impregnated with alkaline or caustic salts to remove acidic gases, specifically $\mathrm{H}_{2} \mathrm{~S}$. According to the disclosed claims of this patent, impregnated activated carbon monoliths exhibit improved adsorption capacity with a shorter mass transfer zone (MTZ) at a substantially lower pressure drop, compared to activated carbon pellets impregnated with the same alkaline salt with a similar loading. The impregnated monolith structures showed a mass transfer zone of 2-4 in. while the mass transfer zone related to impregnated pellets was $8-12$ in. The pressure drops related to these structures were 0.1 and 2 in. $\mathrm{H}_{2} \mathrm{O} / \mathrm{ft}$, respectively. The adsorption capacity of impregnated monoliths was reported to be $70 \mathrm{~kg} \mathrm{H}_{2} \mathrm{~S} / \mathrm{m}^{3}$ bed, while the impregnated particles showed $17 \mathrm{~kg} \mathrm{H}_{2} \mathrm{~S} / \mathrm{m}^{3}$ adsorption capacity.

An important application of structured adsorbents is in adsorption heat pump systems. Due to strict environmental regulations, adsorption heat pumps have gained more attention than conventional mechanical heat pump systems. In spite of rigorous advantages offered by such systems, their coefficient of performance (COP) is still lower than mechanical ones, therefore a wide variety of studies have been conducted to improve the performance of adsorption heat pumps. Among them, the adsorbent bed structure has received attention. Currently, the adsorption heat pump uses the adsorbent materials in the form of pellets, granules or fibers.

In the study conducted by Bonaccorsi et al. [97] open cell copper foams coated with active adsorbent material (zeolite 4A) was applied. In another study, a fast cycle adsorption refrigerator was evaluated using monolithic carbon discs combined with alu- minium fins aimed at enhancing the heat and mass transfer rates by Critoph et al. [98]. Due to low thermal conductivity of the adsorbent materials used in adsorption heat pumps, designers attempted to overcome this deficiency by employing fins or metallic supports such as aluminium, steel or copper for coating adsorbent materials.

\subsection{Use of adsorbent structures in electrical swing adsorption (ESA)}

The concepts of "in situ" heating of adsorbents by electric current in the regeneration step was first proposed 40 years ago [99] and since then many studies have been devoted to apply this principle and develop TSA processes [77-79,100-104]. In electrothermal desorption devises, there are two electric resistances when pellets are being used, namely, the intrinsic resistance of each grain, as well as the resistance due to contact between particles. This implies that the resistance in the bed is anisotropic and the temperature is inhomogeneous along the bed. The use of ohmic heating necessitates a continuous adsorbent for electrical continuity and therefore structured adsorbents are desirable. In the case of fabric or cloth configurations being used in ESA devices, the problem of inhomogeneous temperature and the existence of hot points does not seem to be a severe issue, due to the movement of current in the direction of fibers although there might be a resistance at a microscopic scale between fibers. Monolithic structures are well adapted to application in ESA since the problem of electric contacts between particles in packed beds or even cloths is completely removed.

ESA confers remarkable benefits compared to conventional thermal regenerations, since the heat is delivered directly to the adsorbent media not to the vessel. Furthermore, heating by electricity allows the control of purge gas flow rate and the bed temperature independently from the power applied to obtain the maximum amount of effluent concentration. On the other hand, it must not be forgotten that the electric current is derived from a power station in which heat is used to generate power. Thus using electric current to generate heat is not thermodynamically desirable and should only be examined in cases where direct thermal regeneration is impractical.

Yu et al. [35] used activated carbon monoliths for VOCs removal using electrothermal desorption method. Yu et al. [105,106] investigated the electrothermal swing adsorption (ESA) process with an activated carbon monolith (400 cpsi) as adsorbent for adsorption of toluene vapours. They showed that activated carbon monoliths behave as a semi-conductor and the resistivity decreases as temperature decreases and amount adsorbed increases. The authors showed that the toluene vapours could be effectively enriched to high concentration. Also, they emphasized that the process performance is strongly dependent on the operating conditions and the desorption rate could be controlled by adjusting the electric current and purge gas flow rate. In a more recent study by Grande and Rodrigues [107], electric swing adsorption was employed for the removal of low molar fractions of $\mathrm{CO}_{2}$ from flue gas. These authors utilized carbon honeycomb monolith as an adsorbent in ESA system which showed low electrical resistivity. Based on their findings, direct Joule effect enhanced $\mathrm{CO}_{2}$ desorption rate. However, in order to obtain a higher recovery (more than $89 \%$ ), the $\mathrm{CO}_{2}$ purity was sacrificed to $16 \%$. Place et al. [108] in their patent describe the application of porous monolithic carbon adsorbents for removing of VOCs from gas stream in an ESA system. The regeneration of monoliths that are electrically connected is performed using direct heating by electric current. According to author's claims, due to the low regenerant gas flows required in this system, the additional load on the adsorber is minimized. This is only possible with the electrically heated monoliths where large regenerant gas flows to carry the heat to the reactor are not required. Moreover, due to the low thermal capacity of the monolithic structures they can be 
cooled back sufficiently quickly to the normal adsorption temperatures using feed gases without any adverse effect on the overall adsorption cycle.

\subsection{Criteria for the assessment of adsorbent structure}

From the preceding discussion it is clear that a large number of adsorbent structures are available and some have received close study. It is of interest however to attempt to derive criteria for the assessment of these competing structures for an application. Optimization of adsorbent structures for gas separations was recently studied by Rezaei and Webley [14]. The key results from that study are discussed here.

In a gas separation process, the goal is usually to maximize specific productivity, i.e. to be able to maximize throughput in a given amount of adsorbent. It is therefore necessary to consider an appropriate combination of process parameters to demonstrate how the pressure drop, cycle time and adsorption front affect system performance. As pointed out in Section 2.1, the system specific productivity is the product of the working capacity (moles of gas adsorbed/desorbed per unit mass of adsorbent including binder, support, etc.) and the density of the composite adsorbent. The throughput attainable in a given volume of vessel in a cyclic adsorption system may be expressed as

Throughput $($ TPD $) \propto \frac{\text { gas_production }}{\text { cycle } \times m_{\text {ads }}} \times \frac{\text { cycle }}{\text { day }}$

Specific productivity $=k \frac{W C}{\tau}$

where $m_{a d s}$ is the mass of adsorbent and $k$ is a proportionality constant. The effect of pressure drop on the productivity is to reduce the overall working capacity. Instead of operating between a high pressure $P_{H}$ and a low pressure $P_{L}$, the average bed pressure on adsorption is only $P_{H}-\Delta P / 2$ and the bed pressure on desorption is $P_{L}+\Delta P / 2$. In practice, the bed pressure drop on adsorption and desorption is not equal since the gas velocity is different in these steps. For simplicity in this analysis, we assume they are equal. Thus the pressure difference between adsorption and desorption is approximately diminished from $P_{H}-P_{L}$ to $P_{H}-P_{L}-\Delta P$. Generally (for any isotherm), the working capacity will be reduced by some function of $\Delta P$ written as $f_{1}(\Delta P)$. The situation for linear isotherms is shown in more detail below. A more exact analysis of the effect of pressure can only be obtained through detailed numerical simulations.

The effect of mass transfer zone (MTZ) on specific productivity is to reduce the effective length of bed which also translates to a reduction in working capacity. Again, this can be represented generally as some function $f_{2}$ of the MTZ. The specific productivity can therefore be written as:

Specific productivity $=\frac{k\left[W C-f_{1}(\Delta P)-f_{2}(\mathrm{MTZ})\right]}{\tau}$

where $f_{1}$ and $f_{2}$ are functions of $\Delta P$ and MTZ, respectively. Since the cycle time is inversely proportional to bed velocity

$\tau \propto \frac{1}{U}$

The specific productivity equation can be further rearranged to

specific productivity $=k^{\prime}\left[W C-f_{1}(\Delta P)-f_{2}(\mathrm{MTZ})\right] U$

$$
=k^{\prime}\left[W C-f_{1}(\Delta P(U))-f_{2}(\operatorname{MTZ}(U))\right] U
$$

where $k^{\prime}$ is another proportionality constant and the dependence of pressure drop and mass transfer zone on velocity is made explicit. In order to find $f_{1}$ and $f_{2}$, consider a linear isotherm. For no pressure drop in the system, the ideal amount of adsorbate loading per mass of adsorbent is given by

$W C=\Delta n_{\text {ideal }}=K\left(P_{H}-P_{L}\right)$

As mentioned earlier, pressure drop affects the process by reducing the average pressure swing between feed and blowdown in PSA system. The working capacity for the system with pressure drop and a mass transfer zone is therefore (to a first approximation)

$$
\begin{aligned}
\Delta n_{\text {non-ideal }} & =\left(K\left(\left(P_{H}-\frac{\Delta P}{2}\right)-\left(P_{L}+\frac{\Delta P}{2}\right)\right)\right)\left(1-\frac{M T Z}{L}\right) \\
& =\left(K\left(P_{H}-P_{L}\right)-K \Delta P\right)\left(1-\frac{M T Z}{L}\right) \\
\Delta n_{\text {non-ideal }} & =\left(\Delta n_{\text {ideal }}-K \Delta P\right)\left(1-\frac{M T Z}{L}\right)
\end{aligned}
$$

Therefore, the specific productivity of the adsorbent system can be represented by the following correlation

specific productivity $=k^{\prime}\left(\Delta n_{\text {ideal }}-K \Delta P\right)\left(1-\frac{M T Z}{L}\right) U$

Eq. (18) indicates that specific productivity is proportional to the superficial velocity and inversely proportional to MTZ and pressure drop. Therefore any factor affecting the MTZ and pressure drop may influence the specific productivity. Specifically, the trade-off in specific productivity as a function of velocity is clear. At high velocities, cycle time is reduced however, the pressure drop and MTZ length increases which decrease overall system performance. At low velocities, pressure drop and MTZ effects are small but the long cycle times lead to low specific productivity. The maximum specific productivity as a function of velocity therefore depends strongly on how much MTZ and pressure drop are negatively affected by high velocities. Our earlier study showed that different adsorbent structures achieve their optimum performance at different velocities with structured adsorbents most suited to regions of high velocity where they display their superiority [14].

\subsection{Key areas for future research}

A major driver toward the development of future adsorptive gas separation processes lies in the development of improved sorbent materials. However, these improved materials with better adsorption-desorption capacity must ultimately find their way into a real process for commercial applications that should operate within a rapid PSA or TSA regime or other intensive separation processes to maximize product output per unit mass of adsorbent. As shown above, a wide variety of possible structures have been advanced over the last two decades to overcome existing limitations of pressure drop, mass transfer, etc. In many cases however, some feature of the process is compromised so that inferior performance to a packed bed results. There is a need for research to address the following questions and issues:

(a) What is the optimum generalised gas-solid contacting topology to effect a particular separation and to what extent do the existing structures approach this optimal topology? Research should be directed to developing useful mathematical models which encompass the compensating effects of adsorbent loading, mass transfer, pressure drop, and heat transfer as a function of gas/solid contacting geometry and a function of adsorbent type. These general models should be validated against existing structures and then used to guide further experimental efforts.

(b) The role of thermal management in TSA/PSA processes has not received sufficient attention. Modern manufacturing techniques can create adsorbent structures with heat transfer 
characteristics superior to conventional beads or pellets and future research should be directed to understanding the relationship between adsorbent structure, heat transfer properties and overall system performance. Such techniques may involve the process of producing binderless material to improve heat and mass transport characteristics, production of composite adsorbents with high electrical and thermal conductivity in order to dissipate adsorption heat easier and efficient, employment of suitable support to tailor the thermal properties of the support with mass transfer properties of active material and production of activated carbon monoliths.

(c) The relationship between separation performance, macroscopic adsorbent structure (the subject of this review) and the macro/meso/micropore hierarchy of the adsorbent has not been explored to date. Thus pore engineering must be integrated with systems engineering to produce an overall optimal structure. This is a fertile area for future research into adsorbent structures particularly with the explosion in development of nanoporous materials.

\section{Conclusion}

Conventional gas separation processes using packed beds of beads or granules suffer predominantly from high pressure drop and mass transfer resistance when higher throughputs are required, leading to lower productivity and recovery and higher power consumption. This restricts their application to low throughputs and makes them less attractive compared to the cryogenic processes for large volume production and high productivity. These problems could be overcome by employing alternate adsorbent structures. The major trends toward the design of more compact processes with lower capital and operating cost suggest the use of adsorbent configurations which offer a low pressure drop, fast mass transfer kinetics and high working capacity. The new generation of cyclic adsorption systems with cycle time much shorter than conventional ones necessitates not only an improved process cycle but the employment of novel adsorbent configurations which satisfy almost all requirements of gas process systems in terms of performance and process efficiency.

In this short review, the use of different adsorbent structures with improved performance as a competitive alternate to conventional packed beds of pellets/beads was discussed. Although the advances achieved in the utilization of structured adsorbents during the last decade have been significant, there is still a need to develop generalised rules or criteria for optimizing the selection and design of a particular adsorbent structure for a particular application. These criteria must take into account all of the important characteristics of adsorbents which affect the system behaviour. In our recent study [14] we have qualitatively studied the impact of adsorbent structure on overall performance of adsorption based gas separation systems and formulated a new methodology for evaluating different adsorbent configurations. This methodology could help provide a general overview of adsorbent evaluation and selection. Future work should focus on examining optimal gas-solid contact topologies in a more general sense to provide a theoretical limit to which practical devices could be compared. Such a study could employ concepts such as pore network models coupled to macroscopic flow models to study the dynamic behaviour of the interaction of the adsorption process with the macroscopic flow process. This modelling effort is currently underway in our laboratory. In addition, advanced thermal management opportunities which are possible with adsorbent structures should be studied.

\section{Acknowledgment}

The authors would like to acknowledge the Monash Research Graduate School (MRGS) for providing scholarship support for Fateme Rezaei.

\section{References}

[1] P. Xiao, J. Zhang, P. Webley, G. Li, R. Singh, R. Todd, Adsorption 14 (2008) 575-582.

[2] J. Smolarek, F.W. Leavitt, J.J. Nowobilski, V.E. Bergsten, J.H. Fassbaugh, European Patent, EP0820798 (1998)

[3] S. Ergun, Chem. Eng. Prog. 48 (1952) 89-94

[4] D.M. Ruthven, C. Thaeron, Gas Sep. Purif. 10 (1996) 63-73.

[5] Y.Y. Li, S.P. Perera, B.D. Crittenden, Chem. Eng. Res. Des. 76 (1998) 921-930.

[6] T.C. Golden, C.M.A. Golden, D.P. Zwilling, US Patent US6,565,627 (2003).

[7] A. Patton, B.D. Crittenden, S.P. Perera, Chem. Eng. Res. Des. 82 (2004) 999-1009.

[8] F.C. Patcas, G.I. Garrido, B. Kraushaar-Czarnetzki, Chem. Eng. Sci. 62 (2007) 3984-3990.

[9] D.M. Ruthven, Principles of Adsorption and Adsorption Processes, John Wiley \& Sons, Inc., 1984, p. 243.

[10] R.T. Yang, Gas Separation by Adsorption Processes, John Wiley and Sons, Inc., 1987.

[11] N. Wakao, T. Funazkri, Chem. Eng. Sci. 33 (1978) 1375-1384.

[12] R.D. Hawthorn, AIChE Symp. 70 (1974) 428-438

[13] G. Groppi, L. Giani, E. Tronconi, Ind. Eng. Chem. Res. 46 (2007) 3955-3958

[14] F. Rezaei, P. Webley, Chem. Eng. Sci. (2009), doi:10.1016/j.ces.2009.08.029.

[15] G.I. Taylor, Proc. Phys. Soc. Sect. B 67 (1954) 857-869.

[16] J. Collins, US Patent, US4,026,680 (1977).

[17] V. Gueret, C. Monereau, P. Pullumbi, PCT Int. Appl., W.I.P.O. Patent WO2008037904 (2008).

[18] D.M. Ruthven, Ind. Eng. Chem. Res. 39 (2000) 2127-2131.

[19] S. Irandoust, B. Andersson, Catal. Rev. Sci. Eng. 30 (1988) 341-392.

[20] I.L. Maclaine-Cross, P.J. Banks, Int. J. Heat Mass Transf. 15 (1972) 1225-1242.

[21] A. Kodama, M. Goto, T. Hirose, T.J. Kuma, Chem. Eng. Jpn. 26 (1993) 530-535.

[22] R.E. Kenson, Environ. Prog. 4 (1985) 161-164.

[23] K.P. Gadkaree, Carbon 36 (1998) 981-989.

[24] Y.Y. Li, S.P. Perera, B.D. Crittenden, Chem. Eng. Res. Des. 76 (1998) 931-941.

[25] L. Li, B. Xue, J. Chen, N. Guan, F. Zhang, D. Liu, H. Feng, Appl. Catal. A: Gen. 292 (2005) 312-321.

[26] A. Mosca, J. Hedlund, F.N. Ridha, P. Webley, Adsorption 14 (2008) 687-693.

[27] M. Park, et al., US Patent US 6,171,373 (2001).

[28] G. Li, R. Singh, D. Li, C. Zhao, L. Liu, P. Webley, J. Mater. Chem. (2009), doi:10.1039/b912329f.

[29] J.J. Meyers, A.I. Liapis, J. Chromatogr. A 827 (1998) 197-213.

[30] J.J. Meyers, A.I. Liapis, J. Chromatogr. A 852 (1999) 3-23.

[31] A.I. Liapis, J.J. Meyers, O.K. Crosser, J. Chromatogr. A 865 (1999) 13-25.

[32] F. Brandani, A. Rouse, S. Brandani, D.M. Ruthven, Adsorption 10 (2004) 99-109.

[33] B. Crittenden, A. Patton, C. Jouin, S. Perera, S. Tennison, J.A.B. Echevarria, Adsorption 11 (2005) 537-541.

[34] M. Yates, J. Blanco, P. Avila, M.P. Martin, Micropor. Mesopor. Mater. 37 (2000) 201-208.

[35] F.D. Yu, L.A. Luo, G. Grevillot, J. Chem. Eng. Data 47 (2002) 467-473.

[36] H.S. Kim, J.W. Kim, J.E. Yie, H. Moon, Proceedings of the Third Pacific Basin Conference on Adsorption Science and Technology, vol. 1, 2003, pp. 286-290.

[37] T. Valdes-Solis, M.J.G. Linders, F. Kapteijn, G. Marban, A.B. Fuertes, Chem. Eng. Sci. 59 (2004) 2791-2800.

[38] A. Lapkin, L. Joyce, B.D. Crittenden, Environ. Sci. Technol. 38 (2004) 5815-5823.

[39] D.B. Shah, S.P. Perera, B.D. Crittenden, in: Fundamentals of Adsorption, Boston, 1996, pp. 813-820.

[40] L.Y. Lee, S.P. Perera, B.D. Crittenden, S.T. Kolaczkowski, Adsorpt. Sci. Technol. 18 (2000) 147-170.

[41] C.A. Grande, S. Cavenati, P. Barcia, J. Hammer, H.G. Fritz, A.E. Rodrigues, Chem. Eng. Sci. 61 (2006) 3053-3063.

[42] M. Zabka, M. Minceva, A.E. Rodrigues, Chem. Eng. Process: Process Intens. 45 (2006) 150-160.

[43] M. Zabka, P.S. Gomes, A.E. Rodrigues, Sep. Purif. Technol. 63 (2008) 324-333.

[44] W.A. Cutler, L. He, C.M. Sorensen, L.K. Owens, W.I.P.O. Patent WO2004058372 (2005).

[45] R.P. Ribeiro, T.P. Sauer, F.V. Lopes, R.F. Moreira, C.A. Grande, A.E. Rodrigues, J. Chem. Eng. Data 53 (2008) 2311-2317.

[46] R. Jain, A.I. LaCava, A. Maheshwary, J.R. Ambriano, D.R. Acharya, F.R. Fitch, US Patent US6,521,019 (2003).

[47] L. He, L.K. Owens, W.A. Cutler, C.M. Sorensen, Ceram. Eng. Sci. Proc. 25 (2004) 529-534.

[48] W.S. Kaboord, J.A. Kovacich, D.M. Becher, F.J. Begale, US Patent US2005249645 (2005).

[49] S.R. Jale, F.R. Fitch, S. Dongmin, US Patent US6,436,173 (2002).

[50] W.A. Belding, M.F.P. Delmas, W.D. Holeman, D.A. McDonald, US Patent, US5,685,897 (1997). 
[51] W.A. Belding, M.F.P. Delmas, W.D. Holeman, D.A. McDonald, US Patent US $5,650,221$ (1997).

[52] W.A. Belding, W.D. Holeman, Z. Lavan, R.L. Jones, US Patent US5,580,369 (1996).

[53] W.A. Belding, C.H. Lam, W.D. Holeman, S.L. Janke, US Patent US5,890,372 (1999).

[54] R.A. Macriss, W.F. Rush, S.A. Weil, US Patent US4,012,206 (1977).

[55] A.B. Gorbach, M. Stegmaier, G. Eigenberger, J. Hammer, H.G. Fritz, Adsorption 11 (2005) 515-520.

[56] A. Kodama, Memoirs of the Faculty of Engineering, vol. 40, Kumamoto University, 1996, pp. 313-351.

[57] A. Kodama, K. Andou, M. Ohkura, M. Goto, T. Hirose, J. Chem. Eng. Jpn. 36 (2003) 819-826.

[58] A. Kodama, M. Goto, T. Hirose, T. Kuma, J. Chem. Eng. Jpn. 28 (1995) 19-24.

[59] A. Kodama, M. Goto, T. Hirose, T. Kuma, J. Chem. Eng. Jpn. 27 (1994) 644-649.

[60] A. Kodama, N. Watanabe, T. Hirose, M. Goto, H. Okano, Adsorption 11 (2005) 603-608.

[61] H. Yamauchi, A. Kodama, T. Hirose, H. Okano, K.I. Yamada, Ind. Eng. Chem. Res. 46 (2007) 4316-4322.

[62] Y. Matsukuma, Y. Matsushita, H. Kakigami, G. Inoue, M. Minemoto, A. Yasutake, N. Oka, Kagaku Kogaku Ronbunshu 32 (2006) 138-145.

[63] Y. Matsukuma, K. Sadagata, H. Kakigami, G. Inoue, M. Minemoto, A. Yasutake, N. Oka, Kagaku Kogaku Ronbunshu 32 (2006) 146-152.

[64] B.G. Keefer, C.R. Mclean, US Patent US6,056,804 (2000).

[65] D.J. Connor, D.G. Doman, L. Jeziorowski, B.G. Keefer, B. Larisch, C. McLean, I. Shaw, US Patent US 6,406,523 (2002).

[66] B.G. Keefer, A. Carel, B. Sellars, I. Shaw, B. Larisch, US Patent, US6,692,626 (2004).

[67] B.G. Keefer, US Patent US5,082,473 (1992)

[68] R.T. Maurer, US Patent US5,338,450 (1994).

[69] S. Farooq, C. Thaeron, D.M. Ruthven, Sep. Purif. Technol. 13 (1998) 181-193.

[70] B.G. Keefer, US Patent US6,176,897 (2001)

[71] J.A. Sawad, S. Alizadeh-Khiavi, S. Roy, S.M. Kuznicki, W.I.P.O. Patent WO2005032694 (2005).

[72] E.J. Rode, A.J.J. Boulet, A.M. Pelman, M.L. Babicki, B. Keefer, J.A. Sawada, S. Alizadeh-Khiavi, S. Roy, A.C. Gibbs, S.M. Kuznicki, W.I.P.O. Patent WO200660743432 (2007).

[73] J.T. Richardson, D. Remue, J.K. Hung, Appl. Catal. A: Gen. 250 (2003) 319-329.

[74] K.B. Yoon, Y.J. Lee, Y.S. Park, J.S. Lee, US Patent US2,002,183,407 (2002).

[75] T.C. Golden, C.M.A., Golden, P.J. Battavio, US Patent US6,893,483 (2005).

[76] A. Bailey, F.A.P. Maggs, US Patent US4,234,326 (1980).

[77] M. Petkovska, D. Tondeur, G. Grevillot, J. Granger, M. Mitrovic, Sep. Sci. Technol. 26 (1991) 425-444.

[78] P.D. Sullivan, M.J. Rood, K.J. Hay, S. Qi, J. Environ. Eng. 127 (2001) 217-223.

[79] M. Baudu, P. Le Cloirec, G. Martin, De Charbons Actifs Utilises Pour Le Traitement D'air 13 (1992) 423-435.

[80] J.E. Antia, R. Govind, Appl. Catal. A 131 (1995) 107-120.
[81] J. Hedlund, B.J. Schoeman, J. Sterte, Stud. Surf. Sci. Catal. 105 (1997) 2203-2210.

[82] R. Aiello, F. Crea, F. Testa, A.S. Gattuso, in: I. Kiricsi, J.B. Nagy, H.G. Karge (Eds.), Porous Materials in Environmental Friendly Processes, Elsevier, Amsterdam, 1999, p. 29.

[83] Z. Shan, W.E.J. Van Kooten, O.L. Oudshoorn, J.C. Jansen, H. Van Bekkum, C.M. Van Den Bleek, H.P.A. Calis, Micropor. Mesopor. Mater. 34 (2000) 81-91.

[84] C.D. Madhusoodana, R.N. Das, Y. Kameshima, A. Yasumori, K. Okada, Micropor. Mesopor. Mater. 46 (2001) 249-255.

[85] J. Sterte, J. Hedlund, B.J. Schoeman, Catal. Today 69 (2001) 323-329.

[86] E.I. Basaldella, A. Kikot, J.F. Bengoa, J.C. Tara, Mater. Lett. 52 (2002) 350-354.

[87] M.A. Ulla, R. Mallada, J. Coronas, L. Gutierrez, E. Miro, J. Santamaria, Appl. Catal. A: Gen. 253 (2003) 257-269.

[88] A.E.W. Beers, T.A. Nijhuis, N. Aalders, F. Kapteijn, J.A. Moulijn, Appl. Catal. A: Gen. 243 (2003) 237-250.

[89] J. Coronas, J. Santamaria, Chem. Eng. Sci. 59 (2004) 4879-4885.

[90] J. Hedlund, O. Ohrman, V. Msimang, E. van Steen, W. Bohringer, S. Sibya, K. Moller, Chem. Eng. Sci. 59 (2004) 2647-2657.

[91] K. Nikolajsen, L. Kiwi-Minsker, A. Renken, Chem. Eng. Res. Des. 84 (2006) 562-568.

[92] O. Ohrman, J. Hedlund, J. Sterte, Appl. Catal. A: Gen. 270 (2004) 193-199.

[93] I. Perdana, D. Creaser, I. Made Bendiyasa, Rochmadi, B. Wikan Tyoso Chem. Eng. Sci. 62 (2007)3882-3893.

[94] S. Matsuoka, T. Kodama, J. Izumi, H. Tsutaya, K. Kurosu, H. Someya, J. Nucl. Sci. Technol. 41 (2004) 466-472.

[95] P.A. Barrett, N.A. Stephenson, S.J. Pontonio, W.I.P.O. Patent WO2008051904 (2008).

[96] W.B. Leedy, J.F. Eichelsbacher, T.H. Shelton, US Patent US200810236389 (2008).

[97] L. Bonaccorsi, A. Freni, E. Proverbio, G. Restuccia, F. Russo, Micropor. Mesopor Mater. 91 (2006) 7-14.

[98] R.E. Critoph, T.Z. Telto, L.N.G. Davies, Proc. Inst. Mech. Eng. 214 (2000).

[99] B.M. Fabuss, W.H. Dubois, 63rd Annual Meeting of the Air Pollution Control Association 18 (1970).

[100] W. Hauck, G. Grevillot, A.S. Lamine, Chemie-Ingenieur-Technik 69 (1997) 1138-1142.

[101] M. Petkovska, M. Mitrovic, Chem. Eng. J. Biochem. Eng. J. 53 (1994) 157-165

[102] M. Petkovska, M. Mitrovic, Chem. Eng. Res. Des. 72 (1994) 713-722.

[103] M. Rood, P. Sulliva, K.J. Hay, US Patent, US6,364,936 (2002).

[104] E. Crezee, B.D. Tennison, B.D. Crittenden, Proceedings of 7th World Congress on Chemical Engineering, Glasgow, 2005.

[105] F.D. Yu, L.A. Luo, G. Grevillot, J. Environ. Eng. 130 (2004) 242-248.

[106] F.D. Yu, L. Luo, G. Grevillot, Chem. Eng. Process: Process Intens. 46 (2007) 70-81.

[107] C.A. Grande, A.E. Rodrigues, Int. J. Greenhouse Gas Control 2 (2008) 194-202.

[108] R.N. Place, A.J. Blackburn, S.R. Tennison, A.P. Rawlinson, B.D. Crittenden, US Patent US6,964,695 (2005) 